\title{
The future of hydrogeology
}

\author{
Clifford I. Voss
}

\section{Introduction}

"The Future of Hydrogeology" would seem to be an overly ambitious topic for a theme issue of Hydrogeology Journal or for any other journal. Only a modicum of common sense and experience provides the insight that predicting the future of a science is a task fraught with uncertainty that should be approached with caution and humility. Please be assured that the intent of this issue of the journal is not to predict the future but rather to instigate discussion and to inspire creative thinking about hydrogeology. In their articles, authors have presented personal opinions concerning the future evolution of their subjects based on their experience. This is an acceptable approach, considering that any view of the future can be no more than an educated guess. Most authors have given their opinion after an expert and insightful review of the evolution of their subject to the present time or after reviewing the current state of knowledge or practice of their subject. Consequently, this issue of the Hydrogeology Journal provides an exciting view of potential developments in crucial aspects of hydrogeology founded upon developments to date.

The issue contains 30 articles on a variety of 'future hydrogeology' subjects considered from a variety of viewpoints ranging from philosophical to highly quantitative. There are two article types: full length Papers and four-page Essays. All of the articles have been invited. Regretfully, many important subjects are not addressed in this issue due to both the lack of space and the lack of time and resources to assemble the issue, but there is much here that will satisfy and stimulate readers, covering a broad range of important subjects. Table 1 presents a

Published online: 25 February 2005

(C) Springer-Verlag 2005

\section{I. Voss (®)}

US Geological Survey,

431 National Center,

Reston, Virginia, 20192, USA

e-mail: cvoss@usgs.gov

Tel.: 17036485885

Fax: 17036485274 summary of all subjects and articles included in this issue. In the table, articles have been grouped by the Editor in a somewhat arbitrary manner into six general topics. A few articles appear with both primary and secondary topics and readers may discover additional linkages among article topics. The articles appear in this issue in the same order as in the table. Complete reference information for each article appears in the Table of Contents. Brief discussion of the content of each article follows.

\section{History and philosophy}

\section{Narasimhan}

This author provides an insightful perspective on key developments in the evolution of hydrogeologic science in North America and linkages to developments in other countries. He provides a view of both difficulties and research opportunities in hydrogeology and a view of the future where resources are limited and societies apply hydrogeology to better co-exist as part of linked natural systems.

\section{Schwartz et al.}

If the importance of a research result is the number of citations it receives, then pioneering results are the most important contributions to hydrogeology. The interest in the results and in the subsequent published efforts that it spawns decreases with time. Thus, to make a scientific impact, hydrogeologists are encouraged to avoid ordinary 'follow-on' research and to adopt innovative research strategies and topics. These results and other discussions of research strands are based on interpretations of a citation analysis.

\section{Bredehoeft}

This is a challenging article that asserts that some event, such as collection of new data, proves that the underlying conceptual hydrogeologic model is invalid in roughly $25 \%$ of model analyses. This is termed hydrogeologic 'surprise'. The author asserts that there is no real solution to this problem, and so the hydrogeologist must make a subjective choice of conceptual model, and further, that this implies an uncertainty that is difficult to quantify. Analyzing a larger set of possible conceptual models or a willingness to update conceptual models with time may 
Table 1 Subjects, articles and the six general topics included in "The Future of Hydrogeology"

\begin{tabular}{|c|c|c|c|c|c|c|c|c|}
\hline Author & Subject & $\begin{array}{c}\text { Article } \\
\text { type }\end{array}$ & $\begin{array}{l}\text { History and } \\
\text { philosophy }\end{array}$ & $\begin{array}{l}\text { Geology and } \\
\text { environments }\end{array}$ & Heterogeneity & $\begin{array}{l}\text { Methods } \\
\text { and data }\end{array}$ & $\begin{array}{l}\text { Quantity } \\
\text { and } \\
\text { quality }\end{array}$ & $\begin{array}{l}\text { Society } \\
\text { and } \\
\text { health }\end{array}$ \\
\hline Narasimhan & Historical perspective & Paper & & & & & & \\
\hline Schwartz and others & Evolution of research & Paper & & & & & & \\
\hline Bredehoeft & Conceptual modeling & Paper & & & & & & \\
\hline Lachassagne & A future hydrogeologist & Essay & & & & & & \\
\hline Baker and others & Extraterrestrial hydrogeology & Paper & & & & & & \\
\hline Fisher & Marine hydrogeology & Paper & & & & & & \\
\hline Hancock and others & Ecological hydrogeology & Paper & & & & & & \\
\hline Stober and Bucher & Deep fluids & Essay & & & & & & \\
\hline Simmons & Variable-density fluids & Essay & & & & & & \\
\hline Post & Coastal groundwater & Essay & & & & & & \\
\hline Neuman & Fractured rock hydrology & Paper & & & & & & \\
\hline Bakalowicz & Karst groundwater & Paper & & & & & & \\
\hline de Marsily and others & Spatial heterogeneity & Paper & & & & & & \\
\hline Noetinger and others & Upscaling & Paper & & & & & & \\
\hline Hunt & Percolation theory & Essay & & & & & & \\
\hline Carrera and others & Inverse modeling & Paper & & & & & & \\
\hline Orr and Meystel & Optimization & Paper & & & & & & \\
\hline Hoffman & Satellite remote sensing & Essay & & & & & & \\
\hline Guerin & Hydrogeophysics & Essay & & & & & & \\
\hline Divine and McDonnell & Applied tracers & Essay & & & & & & \\
\hline Renard & Well hydraulics & Essay & & & & & & \\
\hline Glynn and Plummer & Geochemistry & Paper & & & & & & \\
\hline Barcelona & Remediation technologies & Paper & & & & & & \\
\hline Kalf and Wooley & Sustainable yield determination & Paper & & & & & & \\
\hline Dillon & Aquifer recharge management & Essay & & & & & & \\
\hline Konikow and Kendy & Groundwater depletion & Essay & & & & & & \\
\hline Godfrey and Smith & Groundwater risk assessment & Essay & & & & & & \\
\hline Evans and Maslia & Human exposure assessment & Essay & & & & & & \\
\hline Mukherji and Shah & Socio-ecology and governance & Paper & & & & & & \\
\hline \multirow[t]{6}{*}{ Smith and others } & Water and poverty & Essay & & & & & & \\
\hline & & & & & & & & \\
\hline & primary topic & & & & & & & \\
\hline & secondary topic & & & & & & & \\
\hline & & & & & & & & \\
\hline & & & & & & & & \\
\hline
\end{tabular}

improve the situation but does not solve the fundamental problem that model predictions will be highly uncertain. Several real examples of 'surprise' are given as well as a discussion of implications for policy and evaluating the safety of nuclear waste repositories.

\section{Lachassagne}

The author speculates about the life and work of a hydrogeologist in the not-so-distant future.

\section{Geology and environment}

\section{Baker et al.}

An expansive view is provided of subsurface fluid processes on planets, exoplanets and solar system objects. Water has played a major geologic role on Earth and Mars, and likely on Venus. The authors also discuss fluids on Mercury, Earth's moon, Neptune, Kuiper-belt objects, and comets. Subsurface oceans of water or ammoniawater mixtures are active on Europa, Ganymede, Callisto, Titan, and Triton, and possibly on other solar system bodies. This article gives a fascinating view of solar system hydrogeology that contrasts the uniqueness and variety with the similarities of hydrologic processes occurring on these bodies.

\section{Fisher}

Marine hydrogeology is a relatively young field that studies the movement of fluids in the ocean bottom, their interaction with the solid matrix and the impacts of this flow on, for example, alteration of rock and sediments, seafloor ecosystems, and near-shore and seawater quality. Subsea hydrologic measurements are difficult to make, but new methods are being developed to not only determine in-situ shallow properties but also large-scale fluxes. The author reviews methodology, relation of subaerial and subsea hydrogeology, and discusses the hydrogeology of various subsea environments and future research opportunities in the 2/3 of Earth's groundwater systems that lie beneath the ocean floor.

\section{Hancock et al.}

The article provides a practical overview of the importance of groundwater ecology and evolution of this subject area as well as its involvement in geo-bio-chemical 
transformations. Descriptions are given of groundwater fauna and habitats, zones of ecological interest and importance-ecotones and the hyporheic zone. The types of organisms depend on the spatial scale of groundwater flow and interaction with surface water and these may evolve with time due to water flux changes. Groundwater fauna are distinguished by a dependence on light, nutrients, carbon, and space and symbiotic relationships with bacteria. Particular communities exist in caves and at the interface of groundwater with fresh surface water and with subsurface seawater. The authors feel that education of water managers is required for them to understand the impacts of natural and human activities with subsurface ecosystems, particularly considering that subsurface communities have a major impact on groundwater quality.

\section{Stober and Bucher}

This article reviews the current state of the young field that considers the hydrogeology and geochemistry of deep fluids and the deep biosphere of the Earth. The field has applications to understanding of deep Earth processes, structure and fluid behavior. Advances will require collection of new deep data, which is very costly and practically difficult to obtain. One driving force is the potential for geothermal energy development from several kilometers depth. Exciting developments are expected.

\section{Simmons}

It is shown that the effects of varying fluid density on groundwater flow can be important, even for small differences in solute concentration or temperature, and need to be considered in many common situations where variable density is now neglected. Relatively higher fluid density differences can result in fingering flow, which is a process that can be considered to enhance macrodispersion. Few field measurements of unstable density distributions have been made. There is a need to better understand the impact of density-driven flow on large-scale processes, such as thermo-haline convection impacts on ore deposition.

\section{Post}

Coastal aquifers are not only subject to seawater intrusion, but because over half the Earth's population lives along the sea coast, are also subject to anthropomorphic contamination and over-development. Numerical modeling has been well developed to aid in management, but data are most often lacking on land and are often nonexistent offshore, though these data are important for creating an effective model. Further, the movement of sea level affects coastal water resources, even movements long past, and this phenomenon is only beginning to be investigated.

\section{Neuman}

The author states that fractured hard rocks are best characterized by in-situ hydraulic and tracer tests, providing the main data for modeling their hydrologic be- havior. Possible model types reviewed include: Discrete networks of fractures (which have difficulties with defining location and geometry of fractures, fracture properties, and channelized flow within fractures), and, stochastic continua, for example, using indicator statistics or superposed multi-scale continua (here, flow channeling is best represented in a stochastic model of medium permeability and porosity so that channeling patterns can change depending on the direction of hydraulic gradients). Major challenges include: developing understanding of the interaction of fractures and matrix, and the hydraulic behavior at fracture intersections; developing methods for remote imaging of structure; including uncertainty assessments in model analysis results; and using alternative conceptual models for the same site.

\section{Bakalowicz}

This article reviews the nature of karst aquifers and the difficulties in describing flow and transport in these systems. Karst systems vary from those that are only fractured to conduit networks and all gradational variations between these extremes. Groundwater flow interacts with and eventually controls karst structure. A standard averaging volume to obtain large-scale properties cannot be defined for most karst. The author maintains that developed karst should be investigated by methods similar to those used for river-stream systems and by comprehensive methods which require using several approaches to characterize a system. There are real challenges for developing, managing and protecting a karst groundwater reservoir. Quantitative analysis is often only semi-quantitative and usually involves lumped parameter models, but distributed parameter models are still in their early stages of development. The karst network geometry and interaction of conduits and matrix can never be defined with certainty and only the primary spring integrates the behavior of the entire system.

\section{Heterogeneity}

\section{de Marsily et al.}

The authors review geostatistical, facies, and genetic models as well as upscaling. They state that there is a need to do away with 'equivalent porous media' descriptions of heterogeneous geologic materials. Preferably, there is need to better describe geologic structure (at all scales) in a statistical manner (particularly facies descriptions) and include this in model analyses. Estimating facies properties and connectivity should be the goal of new field measurements, and there is need to critically compare existing facies descriptions. Interestingly, the authors discuss when heterogeneity has to be taken into account to appropriately conduct an analysis.

\section{Noetinger et al.}

By considering and prioritizing physico-chemical properties and structure at a full range of length and time scales in stochastic models of aquifer systems, the main 
controls on flow and transport and the main parameters can be found. The article reviews precepts and approaches to upscaling, for example, that behavior of a large complex heterogeneous system can be described by only a few parameters. The authors discuss direct upscaling and by filtering, reduction of the large number of parameters in stochastic models to allow inversion, and upscaling of the advection-dispersion and multiphase-flow equations.

\section{Hunt}

Percolation theory provides the needed theoretical framework for predicting flow and transport in porous media. It is also valid for systems far from the percolation threshold and thus is a fundamental predictor of flow and transport physics for hydrogeologic systems. Percolation theory deals primarily with connectivity rather than permeability (in contrast with most stochastic theories) which is a critical function especially for subsurface transport.

\section{Methods and data}

\section{Carrera et al.}

Inversion methods are compared and contrasted. The authors argue that calibration is really an integral part of the process of modeling and developing understanding of a hydrogeologic system and thus should become a standard part of model application. Automatic calibration makes it easier for the practitioner to concentrate on evaluating different conceptual models-which is the crux of an analysis. Inversion codes should be made friendlier, and should allow use of GIS coverages as well as of geostatistical descriptions of 'soft' geologic information. Inversion should incorporate environmental chemical data. Uncertainty may best be evaluated by Monte Carlo simulation.

\section{Orr and Meystel}

The authors provide an interesting overview of existing optimal management methods and they maintain that these have very limited ability to solve real problems. The reason given is their dependence on numerical models that represent the pertinent system behavior through solution of differential equations. Even with stochastic control models (based on a single numerical model or a model set), the uncertainty in results and prohibitive computational requirements make these approaches impractical. Further, these do not solve the entire problem that consists of optimizing values of interdependent variables at various scales. The authors present a possible future solution as 'intelligent control' that takes into account many types of information simultaneously, optimizing the entire interdependent system through a 'multiresolutional approach'. The article reports some stumbling blocks that need to be overcome in order to apply this new methodology to hydrogeologic system optimization.

\section{Hoffman}

There are new satellite-based measurements of parts of the water cycle at space and time scales not previously possible. Promising future developments will occur in measuring soil moisture, subsurface water storage, subsidence, and in defining shallow geologic structures.

\section{Guerin}

An overview of hydrogeophysical methods is provided, describing measurable quantities and some case studies. There are improvements required in the scale, depth and resolution of measurements as well as in correlating factors, measured via geophysics, with hydrogeologic parameters.

\section{Divine and McDonnell}

The authors briefly review the history of tracing and maintain that, despite limited distance and time scales of tests, tracers will become more widely used in the future. Highly versatile types of tracers may be implemented, possibly based on nanotechnology. Tracer test design and analysis require future additional development.

\section{Renard}

There is need for education to properly use existing methods of hydraulic well testing. Numerical models can be employed for hydraulic test analysis. The author states that despite the historical development of a wide range of analytical methods, these are insufficient and further development is needed.

\section{Glynn and Plummer}

This comprehensive article reviews the history of advances and the state-of-the-art in the application of geochemical data and analysis as one of the most important means of developing knowledge of subsurface hydrologic system behavior. The authors discuss sampling problems, the need to extend geochemical modeling analysis methodology, and they describe several vital topics that require future development as well as some groundwater environments that require more geochemical study.

\section{Quantity and quality}

\section{Barcelona}

The author discusses the evolution of remediation policy and technologies in the USA and proposes the future advent of more-holistic watershed-scale protection procedures. The author ranks highly the sustainability of remediation technologies and states that there is particular need for long-term field experiments. Changes in remediation technology may be required to deal with new contaminants and by-products. Hydrogeologic site characterization is vital to successful remediation.

\section{Kalf and Woolley}

This article revisits, challenges, and clarifies sustainableyield definitions and means to determine sustainable 
yield. It is emphasized that 'sustainable' implies a permanent state and that while some groundwater supplies are indeed sustainable, others are not and must be treated economically as a non-renewable resource.

\section{Dillon}

Active management of aquifer recharge (including enhancing recharge) is not yet a widely used approach, though it is the most effective means of increasing high quality water supply to communities. The author suggests that active management will increase in the future and lists ways forward.

\section{Konikow and Kendy}

This article describes groundwater depletion and gives pertinent examples. Also discussed are the impacts of groundwater depletion, and the need to better assess, manage and respond to depletion. The authors anticipate that the future rate of groundwater depletion will be substantially reduced in many areas because of improved groundwater management policies.

\section{Society and health}

\section{Godfrey and Smith}

The authors emphasize reducing the risk of contamination of water supplies (particularly microbial) in developing countries by careful consideration of localized pathways (e.g. wellhead short circuits). Risk should be managed by quality assurance in all steps of the water delivery process, rather than exclusively by end-product testing.

\section{Evans and Maslia}

Regarding human exposure assessment, knowledge of the hydrogeologic regime is a factor in epidemiological data interpretations regarding exposure to toxic substances that migrate underground. Quantification of uncertainty in hydrogeologic data and probabilistic modeling may improve protection of public health.

\section{Mukherji and Shah}

The authors consider various modes of groundwater use governance (with emphasis on groundwater for irrigation) and their relative success. It is stated that sustainable management of water supplies requires successful integration of groundwater physics, user community behavior and institutional functions, although the social and governance aspects have, so far, been neglected for the most part.

\section{Smith et al.}

The authors argue that there is a great need for understanding and consideration of local social processes in order to more successfully improve conditions (and water supply) in impoverished communities.

\section{Conclusions}

Having assembled and considered the articles contained in this issue of Hydrogeology Journal, it is difficult for the Editor to conclude this Preface without expressing some of his own opinions on particular aspects of hydrogeology's future. These thoughts are partly inspired by some of the challenging and insightful views of this issue's authors.

Hydrogeology is far from being a typical quantitative science. There is rarely any proof of hydrogeologic hypotheses. Each model and each prediction is a hypothesis and there are rarely true tests of these predictions. Hydrogeology is mostly a descriptive science that attempts to be as quantitative as possible regarding descriptions, but without the possibility (in many or most cases) of guaranteeing the accuracy of predictions. Indeed, hydrogeologists should strive to make models more quantitative (rather than qualitative) in order to answer real management questions more precisely. But after answering such a question, what proof is there that their particular model is correct? There may be none. Echoes of this concern appear in several articles contained in this issue.

The two main purposes of hydrogeologic studies are: to generate understanding of basic principles and to solve practical problems. Quantitative science requires that hypotheses be tested, but this is not often possible in hydrogeology (e.g. which method for dealing with heterogeneity is ultimately best?). The Editor's view is that much of the work being done in hydrogeology can be characterized as 'faith-based'. In other words, hydrogeologists (concerned with space and time scales larger than the immediate neighborhood of a production well) 'believe' that their approach is a meaningful and useful way to proceed, but cannot prove it objectively.

If there is no scientific proof of a method, then for practical questions, are very simple approaches to solving problems 'as good' as complex approaches? Complex approaches may be theoretically preferable because they deal with more aspects of processes than do simple ones, but they may not give answers that are more correct. All existing data are generally used to help select and calibrate a complex hydrogeologic model — additional or new data are rarely used to check it. If the model is wrong when checked (the 'conceptual surprise' discussed by Bredehoeft, in this issue), what can be done except to reformulate it somehow so that it fits? Then, if this step is taken, the model again cannot be checked. Does calibration of a complex model with many parameters represent a 'better' representation of reality than any other model? Again, is there any objective proof that complex models are superior to simpler ones for solving practical problems?

The simple mathematical laws of hydrogeology are based on physics that is correct (i.e. can be objectively proven by direct measurements) for simple systems (e.g. at laboratory scale, or for systems with homogeneous properties) - but for real systems, the governing equations are applied to unknown or only partially defined spatial 
and temporal structures of external conditions and internal distributions of equation parameters. Spatial and temporal heterogeneity of hydrogeologic systems is thus a problem that underlies and typifies the 'no proof' concern raised here. The usual response is to select an approach or level of complexity that makes the practitioner 'feel good'insofar as the selected approach agrees with the hydrogeologist's intuition. It may be possible that we cannot do better than this.

Several authors in this issue give bold descriptions of dealing with complex geologic environments and of theoretical means of modeling heterogeneous hydrogeologic systems. However, the article by de Marsily and others states: "Until the large-scale permeability of an aquifer can be reconstructed from small-scale measurements, there will be a credibility problem for our discipline." Indeed, it may not be possible to ever do so and we are left with a permanent credibility problem! One challenge for the future is to determine whether or not this can be done, and if so, to prove in which geologic environments this is possible. There is some hope by the Editor (albeit intuitive!) that certain geologic settings have typical characteristics regarding the spatial variability of their hydrogeologic properties so that some important characteristics of measurements in one place can be transferred to understanding of a similar geologic setting in another place.
It must be clear to the reader by now that the Editor believes that casual use of complex models of processes or of models with complex parameter distributions and many details is neither meaningful nor practically or scientifically justifiable for answering practical hydrogeologic management and engineering questions. In contrast, use of such analysis is well founded for purposes of hydrogeological process research and for development of insight into hydrogeologic processes. Indeed, the insight obtained from such study is the strongest tool a hydrogeologist will ever have for dealing with practical questions.

In summary, 'hydrogeologic science' is not well suited to quantitative prediction and is best suited to providing hydrogeologists with theoretical and science-based intuition that they can apply when suggesting solutions to complex practical problems. Hydrogeologists are faced with being primarily descriptive scientists rather than quantitative scientists, and can employ quantification only to the extent they 'believe' is meaningful and useful. Some hydrogeologic problems cannot be solved - they are too complex. This must be admitted and efforts should rather be applied to solvable problems. It should be a major role of hydrogeologists to help managers define the practical questions that are possible to answer. 